\title{
Erratum: Properties of a Cationic Peroxidase from Citrus jambhiri cv. Adalia
}

\author{
Saleh A. Mohamed • Mohamed O. El-Badry • \\ Ehab A. Drees • Afaf S. Fahmy
}

(C) Springer Science+Business Media, LLC 2011

\section{Erratum to: Appl Biochem Biotechnol (2008) 150:127-137 DOI 10.1007/s12010-008-8142-2}

The original version of this article unfortunately contained a mistake. The affiliation of the third author is incorrect. The correct affiliation is: Division of Biochemistry, Chemistry Department, Faculty of Science, Fayoum University, Fayoum, Egypt.

The online version of the original article can be found at http://dx.doi.org/10.1007/s12010-008-8142-2.

S. A. Mohamed $(\bowtie) \cdot$ M. O. El-Badry $\cdot$ A. S. Fahmy

Molecular Biology Department, National Research Centre, Cairo, Egypt

e-mail: saleh38@hotmail.com

\section{E. A. Drees}

Division of Biochemistry, Chemistry Department, Faculty of Science, Fayoum University, Fayoum, Egypt 